\title{
Fascial Free Flap for Reconstruction of the Dorsolateral Hand and Digits: The Advantage of a Thin Contour
}

\author{
Min Gue Lee ${ }^{1}$, Jin Soo Kim ${ }^{1}$, Dong Chul Lee ${ }^{1}$, Si Young Roh ${ }^{1}$, Kyung Jin Lee ${ }^{1}$, \\ Byeong Kyoo Choi ${ }^{2}$
}

Departments of ${ }^{1}$ Plastic and Reconstructive Surgery and ${ }^{2}$ Radiology, Gwangmyeong Sungae General Hospital, Gwangmyeong, Korea

\begin{abstract}
Background Fascial free flaps have been widely used for reconstruction of the hand because they are thin. However, studies reporting objective data regarding the advantages of this approach are lacking. Thus, we report our experience with such flaps.

Methods Forty-five cases of fascial free flaps between November 2006 and March 2014 were reviewed. Nine cases involving reconstructed dorsal or lateral defects were included. Four anterolateral thigh fascial free flaps and 5 lateral arm fascial free flaps were examined. Maximal flap contour was assessed by measuring reconstructed tissue thickness at the central area from the surface of the skin to below the bone in a vertical manner using ultrasonography and X-ray data. Contralateral regions were examined in the same manner and a comparative analysis was performed. A questionnaire survey regarding aesthetic satisfaction was also administered.

Results All reconstructed parts had a thicker contour than the contralateral side. The average relative percentage of reconstructed tissue thickness was found to be $152 \%$ using ultrasonography and $143 \%$ using $X$-ray imaging. According to the aesthetic satisfaction survey, the average rate of satisfaction for patients was $62 \%$, and satisfaction with the flap contour was $72 \%$.

Conclusions Using a fascial free flap, the reconstructed tissue was approximately $1.5 \times$ as thick as the contour of the normal side, which led to positive responses regarding aesthetic satisfaction.
\end{abstract}

Keywords Fascia / Free tissue flaps / Thinness / Patient satisfaction
Correspondence: Jin Soo Kim Department of Plastic and Reconstructive Surgery, Gwangmyeong Sungae General Hospital, 36 Digital-ro, Gwangmyeong 14241, Korea

Tel: +82-2-2680-7637

Fax: +82-2-2615-7218

E-mail:DRKIM@korea.com

No potential conflict of interest relevant to this article was reported.

Received: 12 May 2016 • Revised: 19 Sep $2016 \bullet$ Accepted: 28 Sep 2016

pISSN: 2234-6163 • elSSN: 2234-6171 • https://doi.org/10.5999/aps.2016.43.6.551 • Arch Plast Surg 2016;43:551-558

\section{INTRODUCTION}

The dorsal skin of the hand is very thin, supple, and aesthetically noticeable. These characteristics should be considered in reconstruction procedures for this area. With recent developments in free-flap surgery, flap survival is no longer the only goal. The aesthetic outcome has become important as well. Bulky flaps are not only unsightly, but can limit function if not serially debulked. The fascial flap, which was first described by Smith [1] in 1980, provides a thin, pliable, and mobile substrate, and has been used by many surgeons utilizing various donor sites [1-9]. Every study regarding the fascial flap highlights its thinness. However, to the best of our knowledge, few studies have provided objective data supporting this claim. In this study, we evaluat- 
ed the thickness of the fascial free flap in objective terms and assessed patients' aesthetic satisfaction with the results.

\section{METHODS}

\section{Patients}

A single-institution study was conducted among patients who had undergone reconstruction using various fascial free flaps from November 2006 to March 2014. To determine whether the swelling had completely regressed, we targeted patients who had undergone surgery and for whom more than one and a half years had elapsed since the operation. Data from 45 patients were culled from a combination of patient charts and radiographic studies. Seventeen cases with an accompanying severe bony deformity due to the initial trauma were excluded because we could not determine a standard point of measurement. Eight cases involving flaps on the fingertip or the volar side were excluded because these flaps were double-folded or included more suprafascial fat with the intent of providing cushioning at the defects, which was inappropriate for the purpose of this study, since our goal was to examine how thin and natural the fascial flap can be. Eleven patients were not available for follow-up; therefore, this study ultimately included a total of 9 patients. An anterolateral thigh fascial free flap was applied in 4 cases, and a lateral arm fascial free flap in 5 cases. In one of these patients, the middle and ring finger were covered simultaneously with a bridged anterolateral thigh fascial free flap, which was later divided, so that the middle and ring fingers were measured sepa- rately. Therefore, a total of 10 points were obtained for the measurement of reconstructed tissue thickness. After 3 weeks, we applied split-thickness skin grafts in all cases. At that time, bed preparation was done with debulking to the desired thinness. The grafts were $0.3 \mathrm{~mm}$ thick.

\section{Measurement and questionnaire}

Ultrasonography was performed to measure the reconstructed tissue thickness. To minimize technical error, all measurements were performed by a single radiologist. A Philips iU22 ultrasound system, equipped with an L15-7io linear array probe (Philips Medical Systems, Foster City, CA, USA), was used for these measurements. Rub-gel (Firson Co., Cheonan, Korea), a glycerin concentrate ultrasonic medium, was mounted on the probe, which was applied to the center of the flap. Flaps have a three-dimensional shape, with the greatest thickness in the center, so that the thickest point in the central quarter of the flap was regarded as the representative flap contour. The perpendicular distance from the skin surface to the bone below was measured in millimeters and the relative percentage in comparison to the contralateral normal side was recorded. A true lateral Xray view of each flap was also analyzed to complement the ultrasonographic data (Fig. 1). The thickest part shown at the shadow of the soft tissue on the X-ray image was likewise measured. The initial defects of 8 patients showed bone exposure and another one showed only tendon exposure. The defects of these deep structures were not severe enough to distort the measurement. Finally, subjective satisfaction with the aesthetic results

Fig. 1. Measurement of reconstructed tissue thickness

The thickest point in the central quarter of the flap was measured. The perpendicular distance from the skin surface to the bone below was measured and compared to the normal skin. (A) A yellow circle indicates fascial flap territory and a blue dotted circle indicates the central area measured by $\mathrm{ul}$ trasonography. $(B, C) A$ red arrow indicates the perpendicular distance from the skin surface to the bone below. (D) The $X$-ray image was measured likewise.
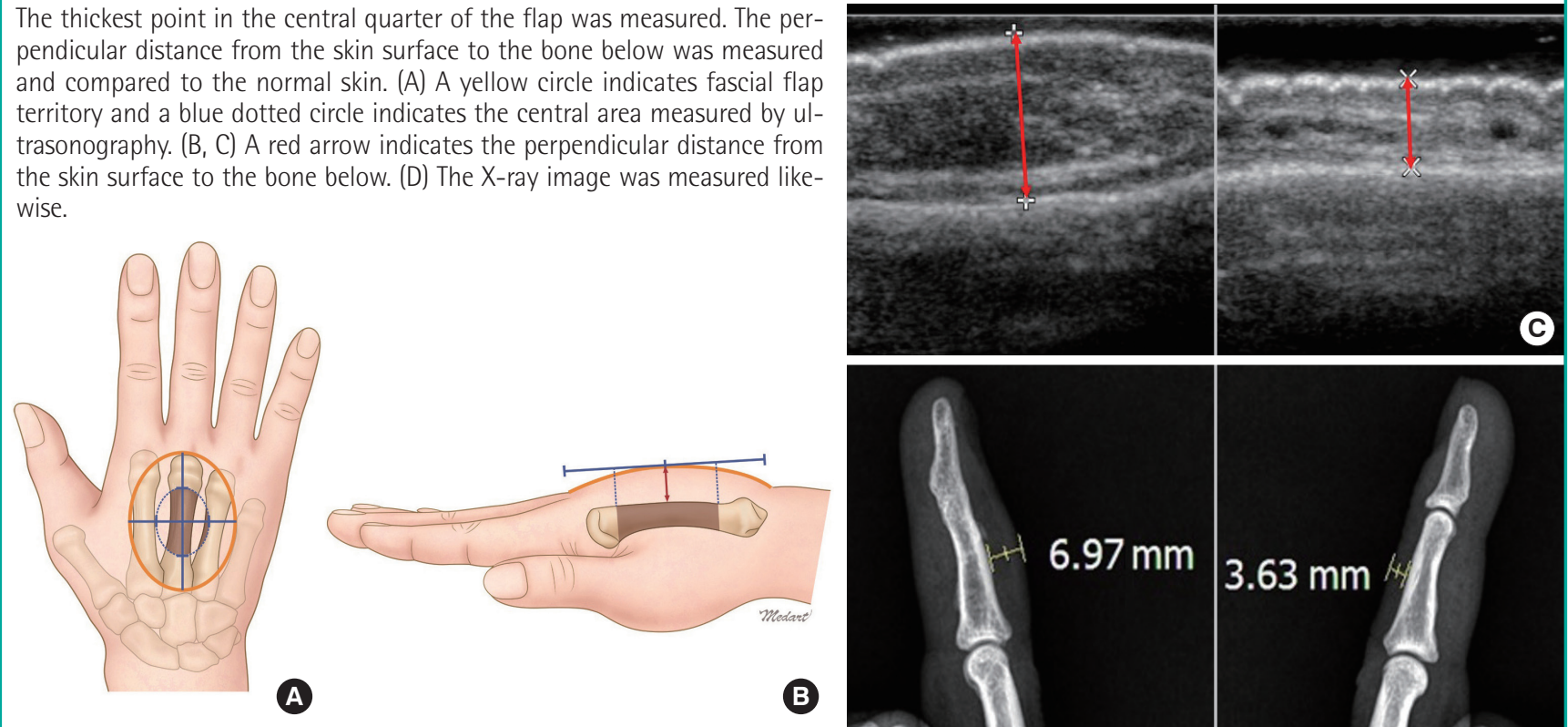

B
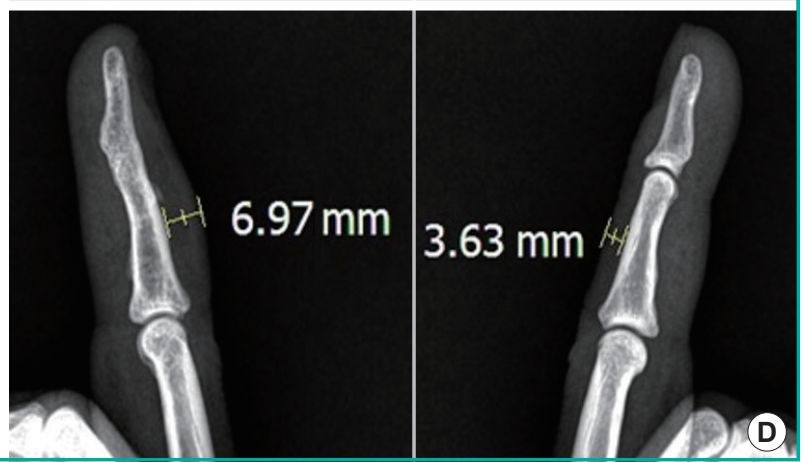
was assessed by the patients using a questionnaire produced by the authors with reference to the Michigan Hand Outcome Questionnaire (Table 1) [10]. Results were rated on a scale from 1 to 5 points ( 1 , strongly disagree; 2 , disagree; 3 , neither agree nor disagree; 4 , agree; 5 , strongly agree; values for questions 6,7 , and 8 are reversed). The raw score was then converted to a range of $0 \%-100 \%$ (with $100 \%$ indicating maximal satisfaction). The responses were analyzed for each patient as well as for each question. For each patient, the percent satisfaction was defined as follows: ([sum of scores of questions] -8$) / 32 \times$ $100 \%$. For each question, the percent satisfaction was defined as follows: ([sum of scores of patients] -9$) / 36 \times 100 \%$.

\section{RESULTS}

Of the 9 patients, 6 were male and 3 were female. The mean age at the time of surgery was 48.5 years (range, 33-56 years). In all patients, surgery was performed using an operative technique described in a previous article $[6,8]$. All patients were right-

\section{Table 1. Aesthetic satisfaction questionnaire}

Q1. Are you satisfying with the contour of the operated hand or fingers?

Q2. Are you satisfying with the overall shape of the operated hand or fingers?

Q3. Are you satisfying with the color of the operated skin?

Q4. Are you satisfying with the scar of the flap donor site?

Q5. Are you satisfying with the scar of the skin graft donor site?

Q6. Does the appearance of your hand make you uncomfortable in public?

Q7. Does the appearance of your hand make you depressed?

Q8. Does the appearance of your hand interfere with your normal social activities? hand dominant; 4 cases involved the right hand and 5 cases involved the left. The locations of the defect were the dorsum of the hand in 3 cases, the dorsum of the finger in 4 cases, and the lateral side of the finger in 3 cases. The causes of injury constituted 5 compression injuries by a press or molding machine, 3 amputation or detrition injuries by a grinder or rotary blade, and 1 contact burn injury. All flaps survived completely and all donor sites were closed directly without tension, causing linear scars that were not broad. A split-thickness skin graft was performed over the fascial flap after 3 weeks. Seven split-thickness skin grafts were harvested from non-glabrous donor sites such as the lateral arm or anterolateral thigh, and 2 of these patients complained of hyperpigmentation on their flap. Glabrous plantar skin was used in 2 cases; a bright color and glabrous texture were detected. Among the initial 45 cases, only 9 cases had no bone defects, and 3 of those cases were among the 9 cases ultimately included in the study. As the bone defects healed, they produced bony spurs that were visible upon ultrasonography, which caused difficulties in measurement. Ideally, cases with bone defects would have been excluded, but cases without such defects are rare. The mean follow-up period was 4 years (range, $1.5-8$ years) (Table 2 ).

The thickness measured by ultrasonography and X-ray imaging showed similar results, and the contour of all flaps was greater than that of the contralateral normal side. The average relative percentage of reconstructed tissue thickness based on ultrasonographic measurements was $152 \%$ (range, 112\%-194\%), and for X-ray measurements 143\% (range, 117\%-192\%) (Fig. 2). The group with anterolateral thigh fascial free flaps measured $148 \%$ (range, $112 \%-189 \%$ ), and those with a lateral arm flap

Table 2. Demographics of patients according to surgical procedure

\begin{tabular}{|c|c|c|c|c|c|c|c|c|}
\hline $\begin{array}{l}\text { Patient } \\
\text { no. }\end{array}$ & $\begin{array}{l}\text { Sex/Age } \\
(y r)\end{array}$ & Side & Location & $\begin{array}{l}\text { Cause of } \\
\text { injury }\end{array}$ & Procedure & $\begin{array}{l}\text { Flap size } \\
\text { (cm) }\end{array}$ & $\begin{array}{l}\text { Secondary } \\
\text { procedure }\end{array}$ & Complication \\
\hline 1 & Male/48 & $\mathrm{L}$ & $\begin{array}{l}\text { Middle and ring finger } \\
\text { middle phalanx dorsum }\end{array}$ & Heated press & $\begin{array}{l}\text { Anterolateral thigh fascial } \\
\text { free flap }\end{array}$ & $5 \times 10$ & $\begin{array}{l}\text { STSG (thigh) } \\
\text { Division }\end{array}$ & None \\
\hline 2 & Female/56 & $\mathrm{R}$ & $\begin{array}{l}\text { Wrist and hand } \\
\text { dorsoradial }\end{array}$ & Cooler motor & $\begin{array}{l}\text { Anterolateral thigh fascial } \\
\text { free flap }\end{array}$ & $8 \times 12$ & STSG (thigh) & Knee pain \\
\hline 3 & Female/49 & $\mathrm{L}$ & Hand dorsum & Rotary blade & Lateral arm fascia free flap & $3 \times 8$ & STSG (thigh) & None \\
\hline 4 & Male/54 & $\mathrm{L}$ & $\begin{array}{l}\text { Middle finger middle } \\
\text { phalanx dorsum }\end{array}$ & Grinder & Lateral arm fascia free flap & $3 \times 6$ & STSG (plantar) & None \\
\hline 5 & Male/56 & $\mathrm{L}$ & $\begin{array}{l}\text { Little finger proximal } \\
\text { phalanx dorsum }\end{array}$ & Press & $\begin{array}{l}\text { Anterolateral thigh fascial } \\
\text { free flap }\end{array}$ & $4 \times 7$ & STSG (plantar) & None \\
\hline 6 & Female/55 & $\mathrm{R}$ & $\begin{array}{l}\text { Little finger middle } \\
\text { phalanx ulnar }\end{array}$ & Blender & Lateral arm fascia free flap & $3 \times 5$ & STSG (upper arm) & None \\
\hline 7 & Male/33 & $\mathrm{R}$ & $\begin{array}{l}\text { Index finger distal phalanx } \\
\text { ulnar }\end{array}$ & Press & Lateral arm fascia free flap & $1 \times 2.5$ & $\begin{array}{l}\text { Local flap and STSG } \\
\quad \text { (upper arm) }\end{array}$ & Hyperpigmentation \\
\hline 8 & Male/42 & $\mathrm{R}$ & Hand dorsum & Mold & $\begin{array}{l}\text { Anterolateral thigh fascial } \\
\text { free flap }\end{array}$ & $4 \times 8$ & STSG (thigh) & Hyperpigmentation \\
\hline 9 & Male/44 & $\mathrm{L}$ & $\begin{array}{l}\text { Index finger proximal } \\
\text { phalanx ulnar }\end{array}$ & Mold & Lateral arm fascia free flap & $2.5 \times 4$ & STSG (upper arm) & $\begin{array}{l}\text { STSG donor itching } \\
\text { scar }\end{array}$ \\
\hline
\end{tabular}




\section{Fig. 2. Relative percentage of reconstructed tissue thickness}

The contour of all fascial flaps was thicker than that of the contralateral normal side. The average relative percentage of reconstructed tissue thickness assessed on ultrasonography was 152\%, similar to $143 \%$ assessed using X-ray imaging.

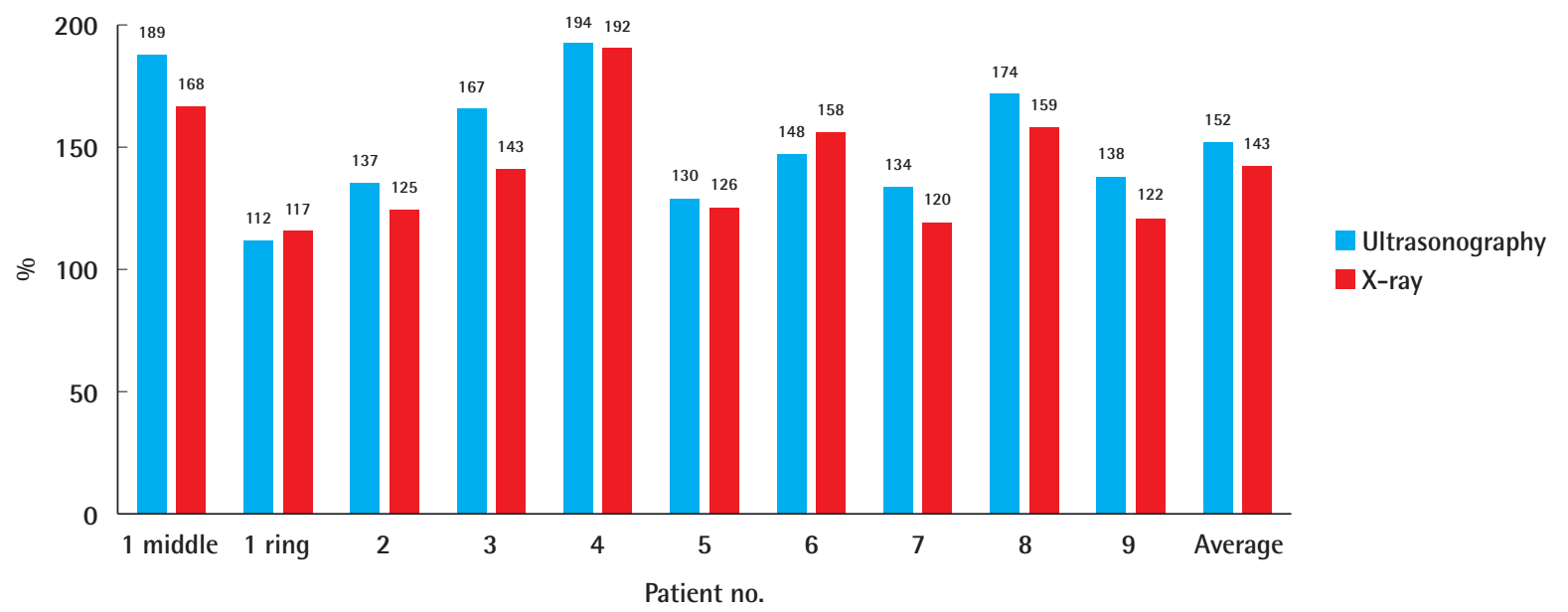

measured 156\% (range, 134\%-194\%) in ultrasonography. None of the patients complained about the flap contour, requiring further flap debulking.

On the satisfaction questionnaire, the mean score for patients' satisfaction was $62 \%$ (range, $25 \%-84 \%$ ), and female patients had the 2 lowest scores (patient 3, 25\%; patient 6, 38\%). In particular, patient 3 reported $0 \%$ satisfaction for all questions about mood and social problems. The mean score for all questions was $61 \%$ (range, 50\%-75\%). The scores for satisfaction with contour (Q1) and the scar of skin graft donor site (Q5) were relatively high ( $72 \%$ and $75 \%$, respectively). Satisfaction with the skin color of the reconstructed site (Q3) was 69\%. Lower scores of 58\% and 56\% were observed for the overall shape (Q2) and scar of the flap donor site (Q4), respectively. Scores on questions about mood or social problems (Q6-8) were also low (Table 3).

\section{Case 1}

A 48-year-old male suffered a fourth-degree burn injury by a heated press on the middle phalanx of the left middle and ring fingers. After radical debridement, flap reconstruction was required for defects with tendon and bone exposure. An anterolateral thigh fascial free flap measuring $5 \mathrm{~cm} \times 10 \mathrm{~cm}$ was elevated and inset as a bridged shape to cover the middle and ring fingers simultaneously. The perforator of the flap was anastomosed end-to-end to the radial proper digital artery of the middle finger and one vena comitans to the subcutaneous vein. After 3 weeks, a split-thickness skin graft was applied, and division was performed 2 months later. Eight years later, his middle finger showed $189 \%$ relative thickness, and his ring finger showed a

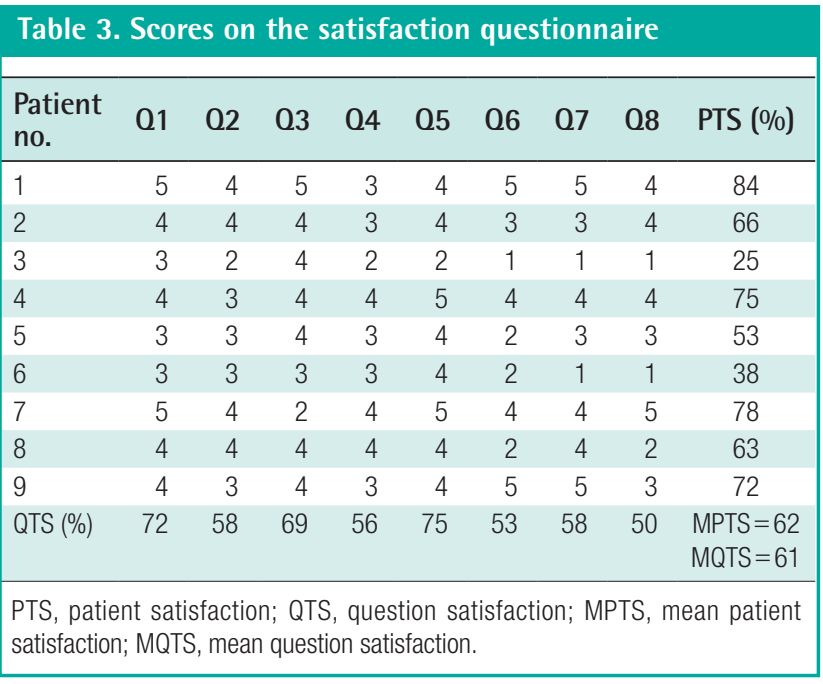

relative thickness of $112 \%$. The final contour was natural and he reported the highest satisfaction score of all patients (84\%). A slight extension lag remained but the overall range of motion was satisfactory (Fig. 3).

\section{Case 3}

A 49-year-old female sustained complete amputation of the left index, middle, and ring fingers by a rotary blade. The amputation levels were at the base of the proximal phalanx for the index and middle finger and at the proximal interphalangeal joint for the ring finger. Severe accompanying crushing injuries were observed throughout the amputated digits, thumb, and involved dorsal hand. The largest segment of the sliced digits was replanted to the middle finger to facilitate later pinching motions, and composite grafts were performed. However, tissue necrosis oc- 


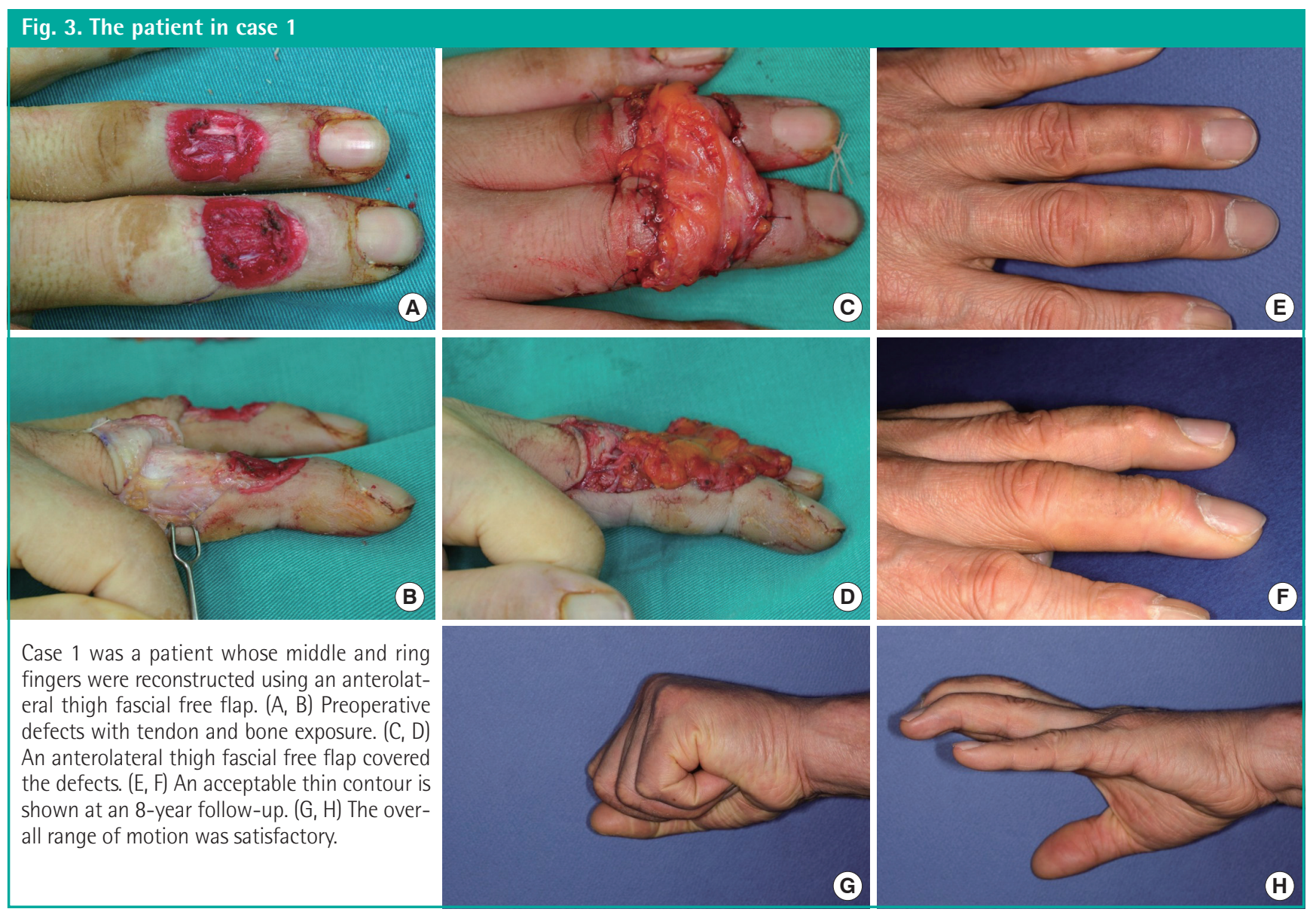

curred at the tip and dorsum of the middle finger and hand dorsum. Following debridement, a lateral arm fascial free flap measuring $3 \mathrm{~cm} \times 8 \mathrm{~cm}$ was elevated, including a $1-\mathrm{cm} \times 2-\mathrm{cm}$ skin paddle for the fingertip. The perforator of the flap was anastomosed end-to-end to the radial artery at the snuffbox and one vena comitans to the subcutaneous vein. After 3 weeks, she underwent a split-thickness skin graft. Her postoperative recovery was uneventful, and at follow-up 3 years and 2 months later, the reconstructed tissue showed a relative thickness of $167 \%$. However, her satisfaction score was the lowest of all patients (25\%) (Fig. 4).

\section{DISCUSSION}

In this study, we confirmed the importance of thin reconstruction for the dorsolateral skin of the hand and fingers. The fascial free flap is thin enough to produce an acceptable outcome, but the requirement of an additional skin graft is a disadvantage. Some authors have pointed out this flaw and prefer a thinned fasciocutaneous flap to a fascial flap. To obtain a thinner fasciocutaneous flap, aggressive defatting should be performed with preservation of the subdermal plexus; however, excessive defat- ting may cause necrosis of the distal flap [11-13]. Nojima et al. [14] reported that when an anterolateral thigh fasciocutaneous free flap was thinned to $6-8 \mathrm{~mm}$, the resultant overall vascular territory was $81.8 \%$ of what was observed in an unthinned flap. Limited success has been reported in some Western studies using thinned anterolateral thigh perforator flaps, and these studies have argued that thinning is best performed as a secondary procedure $[15,16]$. Whether a fascial flap with a skin graft or a thinned fasciocutaneous flap is better is, in many cases, a matter of the surgeon's preference, and further studies are required.

The fascia itself is indistinguishable and irregular under ultrasonography, and we therefore could not measure the actual flap thickness. Instead, we decided to measure the reconstructed tissue thickness from the skin surface to the underlying bone and compare it with the contralateral normal side at the same point, because the bone is clearly defined, allowing more accurate measurements. In addition, the key point for the patient is the degree of similarity between the reconstructed contour and the normal shape, not the flap thickness itself. Therefore, we think that this method was suitable for the purpose of this study. However, most patients who required flap reconstruction for their hands had accompanying fractures, bone defects, and am- 


\section{Fig. 4. The patient in case 3}

Case 3 was a patient whose hand was reconstructed using a lateral arm fascial free flap. (A) The initial mutilated state of the left hand after amputation. (B) A lateral arm fascial free flap covered the defects. (C, D) Follow-up at 3 years and 2 months.
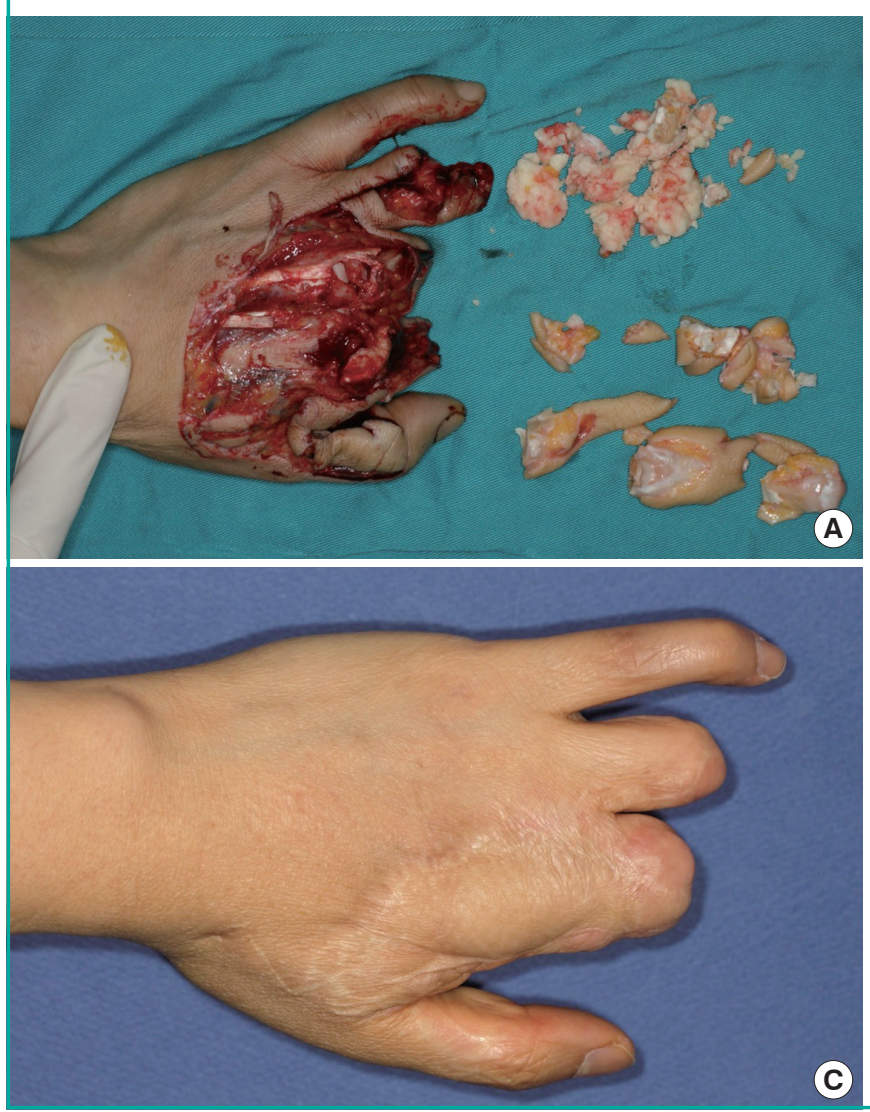

putations due to the severe initial trauma. It was necessary for us to find undeformed bony points for measurement, and in this process, irregular bony spurs were observed under ultrasonography, causing difficulty in the actual measurement of the true thickness. This problem of the bony basement limited the number of ideal cases, which was a major limitation of this study. In most cases, injuries were by machine; however, burn patients have fewer bony deformations capable of causing this problem. Therefore, a cooperative study with a large burn center would be a productive source of further data.

Severe accompanying damage also affected patients' satisfaction. Patient 3, who showed the lowest score on the aesthetic satisfaction questionnaire, had severe accompanying crushing amputation, and this might have led her to respond to the questionnaire in a way that was not limited to the flap alone. Gender may also have affected patients' reported satisfaction. All patients reporting high satisfaction (over $70 \%$ ) were male with no other accompanying damage except the flap coverage site.

Our considerations for selection of a skin graft donor site were skin proximity to the flap donor site, graft size, patient preference, and color and texture matching. Some authors reported
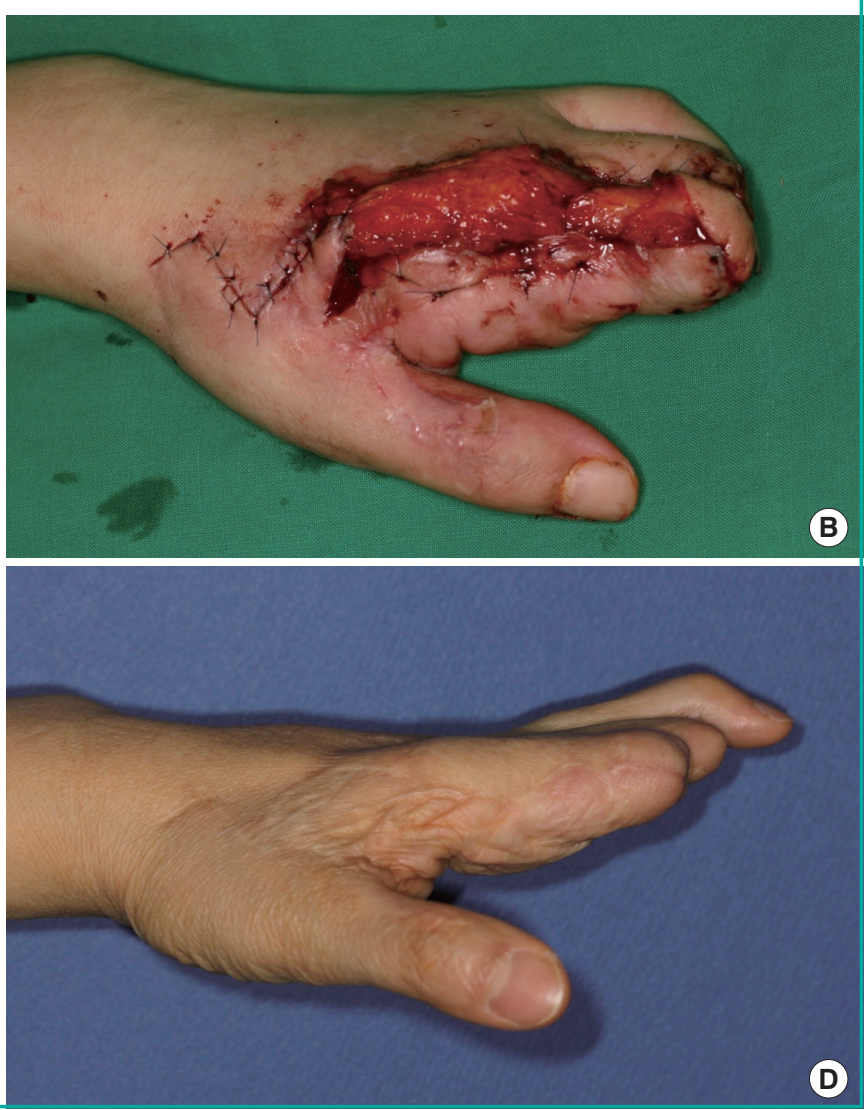

that they prefer a glabrous donor site for palmar or plantar defects, because the result is glabrous and demonstrates good color matching with the surrounding skin $[17,18]$. Carty et al. [4] reported that the texture of the final skin was different according to the donor site of the skin graft that covers the fascial flap: non-glabrous, thigh or buttock; or glabrous, hypothenar or plantar. We also observed that the color and texture of the skin graft on the fascial flap resembled that of the donor site and agree with this concept of "restoring tissue with like tissue." This kind of meticulous consideration leads to optimal outcomes.

We performed split-thickness skin grafts 3 weeks after the operation. There are 4 reasons for delaying instead of performing an immediate skin graft. First, the tie-over or compressive dressing on skin graft can compromise the circulation of the fascial free flap. Second, it is difficult to monitor the flap circulation over the skin graft. Third, the fascial free flap provides an irregular bed when an immediate skin graft is performed. Fourth, it is possible to perform debulking to the desired thinness at 3 weeks, while a regular bed for the skin graft is prepared. In this process, the difference of flap contour according to body mass index, donor site, and location of the pedicle can be minimized, 
and this is an advantage of the fascial flap over the fasciocutaneous flap. A delayed skin graft has the disadvantage of extending the hospital stay, but otherwise we think that the benefits outweigh the drawbacks.

Patients appear to react more strongly to scars made by surgical incisions, and surgeons should therefore take care to minimize scarring at the donor site. It has been reported that primary closure of the donor site can be performed for defects less than $5 \mathrm{~cm}$ in width for a lateral arm skin flap and $8 \mathrm{~cm}$ for an anterolateral thigh skin flap $[9,19]$. However, excessive tension on the closed wound can result in a noticeable scar. Thankappan et al. [20] reported a $75 \%$ incidence of broad donor scars in 37 patients with a lateral arm free flap. In this respect, fascial free flaps have the obvious advantage of reducing scar formation on the donor site.

Measurements of flap thickness using ultrasonography have been previously performed in another study. Nakayama et al. [21] measured the preoperative thickness of the donor anterolateral thigh using ultrasonography from the surface to deep muscle fascia. In 31 head and neck cancer patients, the mean thickness of the donor thigh tissue was $7.1 \mathrm{~mm}$. This value seems to be acceptable for thin reconstruction; however, as Nakayama et al. [21] described previously, due to changes in skin tension, the flap thickness prior to harvesting may differ from the actual thickness after harvesting. We assessed the final flap contour compared to the contralateral normal side using ultrasonography, and, to the best of our knowledge, this was the first attempt to do so. We think that similar techniques of evaluating the results of reconstruction with the goal of improving the aesthetic results can contribute to future studies.

As discussed above, fascial free flaps can be applied easily and safely to the reconstruction of dorsolateral hand and finger defects that require a thin, pliable, and mobile substrate, and they provide consistent results. Satisfaction with the contours was high and additional flap debulking was not necessary. The fascial free flap should be considered an effective option for thin reconstruction.

\section{REFERENCES}

1. Smith RA. The free fascial scalp flap. Plast Reconstr Surg 1980;66:204-9.

2. Upton J, Rogers C, Durham-Smith G, et al. Clinical applications of free temporoparietal flaps in hand reconstruction. J Hand Surg Am 1986;11:475-83.

3. Brent B, Upton J, Acland RD, et al. Experience with the temporoparietal fascial free flap. Plast Reconstr Surg 1985;76: $177-88$.
4. Carty MJ, Taghinia A, Upton J. Fascial flap reconstruction of the hand: a single surgeon's 30-year experience. Plast Reconstr Surg 2010;125:953-62.

5. Taghinia AH, Carty M, Upton J. Fascial flaps for hand reconstruction.J Hand Surg Am 2010;35:1351-5.

6. Hsieh $\mathrm{CH}$, Yang CC, Kuo YR, et al. Free anterolateral thigh adipofascial perforator flap. Plast Reconstr Surg 2003;112: 976-82.

7. Reyes FA, Burkhalter WE. The fascial radial flap. J Hand Surg Am 1988;13:432-7.

8. Yousif NJ, Warren R, Matloub HS, et al. The lateral arm fascial free flap: its anatomy and use in reconstruction. Plast Reconstr Surg 1990;86:1138-45.

9. Chen HC, el-Gammal TA. The lateral arm fascial free flap for resurfacing of the hand and fingers. Plast Reconstr Surg 1997;99:454-9.

10. Chung KC, Pillsbury MS, Walters MR, et al. Reliability and validity testing of the Michigan Hand Outcomes Questionnaire. J Hand Surg Am 1998;23:575-87.

11. Kimura N, Satoh K. Consideration of a thin flap as an entity and clinical applications of the thin anterolateral thigh flap. Plast Reconstr Surg 1996;97:985-92.

12. Kimura N, Satoh K, Hasumi T, et al. Clinical application of the free thin anterolateral thigh flap in 31 consecutive patients. Plast Reconstr Surg 2001;108:1197-208.

13. Koshima I, Fukuda H, Yamamoto H, et al. Free anterolateral thigh flaps for reconstruction of head and neck defects. Plast Reconstr Surg 1993;92:421-8.

14. Nojima K, Brown SA, Acikel C, et al. Defining vascular supply and territory of thinned perforator flaps: part I. Anterolateral thigh perforator flap. Plast Reconstr Surg 2005; 116:182-93.

15. Alkureishi LW, Shaw-Dunn J, Ross GL. Effects of thinning the anterolateral thigh flap on the blood supply to the skin. Br J Plast Surg 2003;56:401-8.

16. Ross GL, Dunn R, Kirkpatrick J, et al. To thin or not to thin: the use of the anterolateral thigh flap in the reconstruction of intraoral defects. Br J Plast Surg 2003;56:409-13.

17. Wu LC, Gottlieb LJ. Glabrous dermal grafting: a 12-year experience with the functional and aesthetic restoration of palmar and plantar skin defects. Plast Reconstr Surg 2005;116: 1679-85.

18. Friel MT, Duquette SP, Ranganath B, et al. The use of glabrous dkins grafts in the treatment of pediatric palmar hand burns. Ann Plast Surg 2015;75:153-7.

19. Adani R, Tarallo L, Marcoccio I, et al. Hand reconstruction using the thin anterolateral thigh flap. Plast Reconstr Surg 2005;116:467-73.

20. Thankappan K, Kuriakose MA, Chatni SS, et al. Lateral arm 
free flap for oral tongue reconstruction: an analysis of surgical details, morbidity, and functional and aesthetic outcome. Ann Plast Surg 2011;66:261-6.

21. Nakayama B, Hyodo I, Hasegawa Y, et al. Role of the antero- lateral thigh flap in head and neck reconstruction: advantages of moderate skin and subcutaneous thickness. J Reconstr Microsurg 2002;18:141-6. 